DESIGN AND ANALYSIS OF WHEEL HUB FOR STUDENT FORMULA CAR

\title{
PONSHANMUGAKUMAR $^{1} \&$ N. MANOHARAN ${ }^{2}$
}

${ }^{I}$ Research Scholar, Department of Mechanical Engineering, AMET University, Chennai, Tamil Nadu, India

${ }^{2}$ Pro Vice-Chancellor (Research), AMET University, Chennai, Tamilnadu, India

\begin{abstract}
In the current outline of Wheel centre point utilized for Student equation autos, the brake plates can't be evacuated effortlessly since the circle is mounted in the middle of the knuckle and centre. If there should be an occurrence of a curve or some other harm to the ring, the substitution of the plate ends up plainly troublesome. Additionally utilising OEM centre and knuckle that is used for business vehicles bring about increment of unsprung mass, which ought to be kept away from in Student equation autos for enhancing the execution. In this outline, the previously mentioned challenges have overcome by overhauling the centre point such that the brake circle could be efficiently expelled by simply evacuating the haggle calliper and furthermore it will have lessened weight when contrasted with existing OEM centre point. A CAD Model produced in light of the required weariness life cycles. The strengths following up on the centre point were computed, and direct static auxiliary examination performed on the wheel centre point for three distinct materials utilising ANSYS Finite Element code V 16.2. The possible weariness quality contrasted and the anxiety gotten from the initial investigation for every document.

KEYWORDS: Knuckle and Centre, OEM Centre, CAD Model \& The Anxiety Gotten
\end{abstract}

Received: Oct 05, 2017; Accepted: Oct 24, 2017; Published: Jan 30, 2018; Paper Id.: IJMPERDFEB201893

\section{INTRODUCTION}

The current models of wheel centres are utilised as a part of Student recipe auto (SF auto) which are taking an interest in occasions like FSAE; SUPRA requires destroying the whole wheel get together to remove the brake plate amid harm or break of the circle, which expends tremendous time. If there should be an occurrence of OEM hub, ( Yang, Y. P., 'et. al'2004) (Wrobel, R. \& Mellor, P. H., 2008), the mass is colossal which will influence the execution of the SF auto as far as weight.( Luo, S. J., 'et. al' 2012) (Vogwell, J., 1998) (JAYAKUMAR, N. 'et.al' 2014)The target of this venture is to outline a centre point for SF auto in which the circle rotor can be efficiently evacuated in the event of harm with decreased weight when contrasted with OEM centre point.( Craig, C., \& Passmore, M. A. 2014) Since the circle in the SF auto is subjected to different tests like continuance, slide cushion, speeding up, autocross and brake test,( Popa, C. E. 2005)a requirement for the straightforward and snappy expulsion of brake plate for substitution is essential. The proposed configuration disposes of the above-said trouble by enhancing compatibility and furthermore diminished weight (Salter, J. I., \& Wittek, A. 2011) (Bakar, M. A., 'et.al'2011)The weakness life prerequisite of the wheel centre points that utilised for SF auto is likewise less when contrasted with the weariness life of the OEM centre points. Thus the adjusted wheel centre point is intended for the required exhaustion life (A. Aravindkumar, 2014)

\section{RELATED WORK}

(Riley, W. B., \& George, A. R. 2002) The paper presents a few of the critical ideas of edge plan both 
scientific and trial. The distinctive stacking conditions and prerequisites of the vehicle outline are first talked about concentrating on street data sources and load ways inside the structure. Next, a basic spring model is created to decide focuses for edge and general frame solidness.

(Theander, A. 2004) In January of 2004,) the Formula Student venture began at KTH including once again seventy understudies. The point of this proposition work is to plan the suspension and directing geometry for the racing auto is constructed. The outline should meet the requests caused by the several occasions in the opposition. The plan displayed here will then be actualised into the undercarriage worked by understudies taking an interest in the task.

(Jawad, B. A., \& Polega, B. D. 2002) This paper is a prologue to the outline of suspension parts for a Formula SAE auto. Recipe SAE is an understudy rivalry where undergrads consider, framework, manufacture, and contend with a little equation style open wheel dashing auto. The suspension segments canvassed in this paper incorporate control arms, uprights, shafts, centres, pull rods, and rockers.

(Shaik, A. F. B., \& Srinivas, C. L. 2012)This article learns about the model of a plate brake utilised as a part of Honda Civic. Coupled field examination (Structural+Thermal) is done on the circle brake. The materials used are Cast Iron. The study is likewise done by changing the outline of circle brake.

(Gaffney, E. F., \& Salinas, A. R. 1997)This paper is a prologue to Formula SAE® (FSAE) suspension and edge configuration in light of the experience of the outline group at UM-Rolla. The essential hypotheses and procedures for outlining these frameworks are introduced so new teams will have a standard for their first FSAE plan.

\section{MODELING AND ANALYSIS}

The wheel centre point utilised here are planned by considering the measurements of the gathering parts, which are the wheel bearing, knuckle, wheel edge, brake circle and half shaft. Doing subsystem investigation will give more precise anxiety comes about. Subsequently, the whole wheel gets together was taken for research to understand push following up on wheel centre point. The wheel get together was coincided with tetrahedral components, and the crosssection are refined close to the anxiety concentrated ranges. The heaps were connected and the subsequent Von Mises stretch following up on the wheel centre point was acquired.

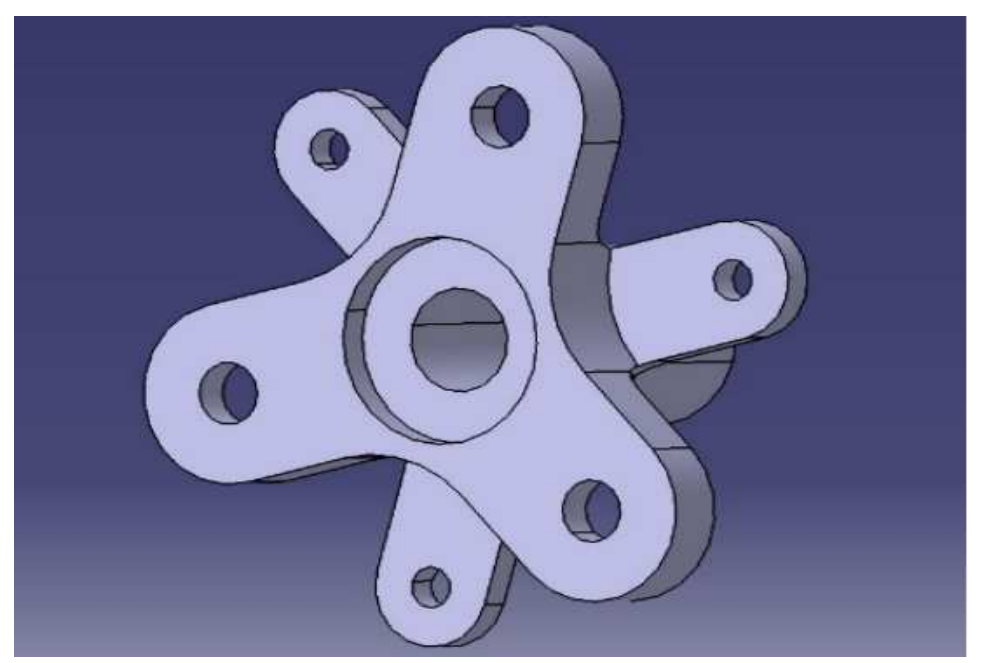

Figure 1: 3D Model of the Wheel Hub 


\section{MESHING}

Mesh generation is the practice of generating a polygonal or polyhedral mesh that approximates a geometric domain. The term "grid generation" is often used interchangeably. Typical uses are for rendering to a computer screen or for physical simulation such as finite element analysis or computational fluid dynamics.

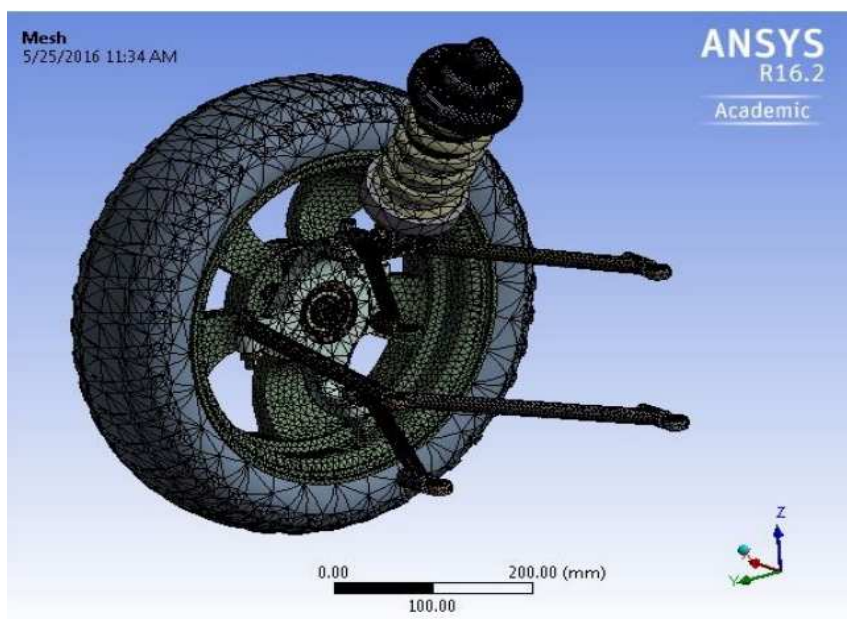

Figure 2: Meshing of the Model in Ansys

\section{RESULT \& DISCUSSIONS}

\section{Stress}

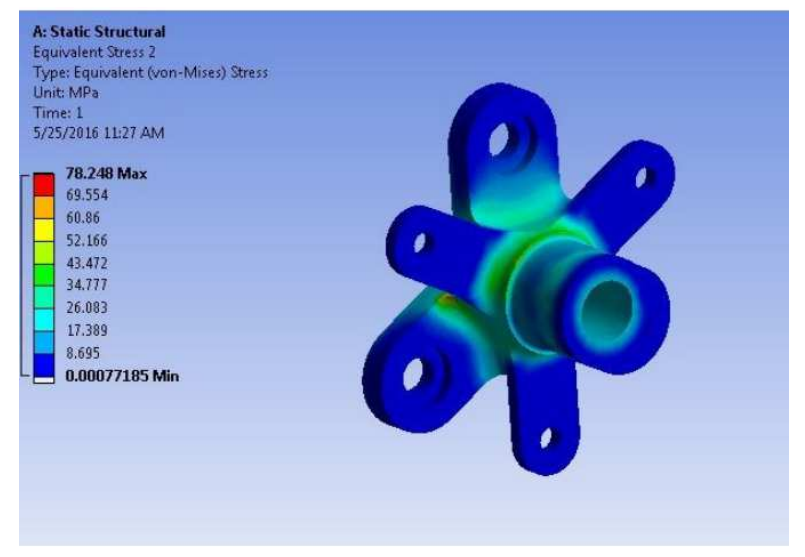

Figure 3: Total Stress for EN 8 Material

The above figure shows the result of total stress of the hub for the EN8 by using the ANSYS workbench software. In the figure 3 the multi colors are showed. The colors denote the safe and unsafe portions of the hub. The blue color denotes the minimum stress and the green color denotes the maximum stress. 


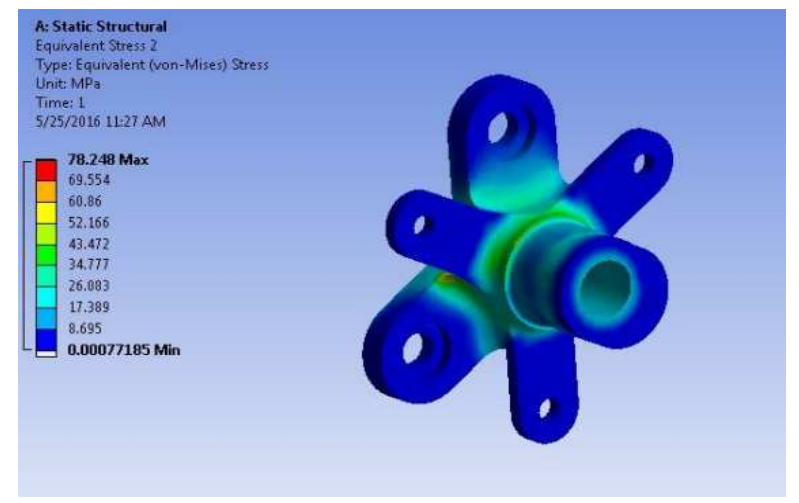

Figure 4: Total Stress for EN24 Material

The above figure shows the result of total stress of the hub for the EN24 by using the ANSYS workbench software. In the figure 4 the multi colors are showed. The colors denote the safe and unsafe portions of the hub. The blue color denotes the minimum stress and the green color denotes the maximum stress.

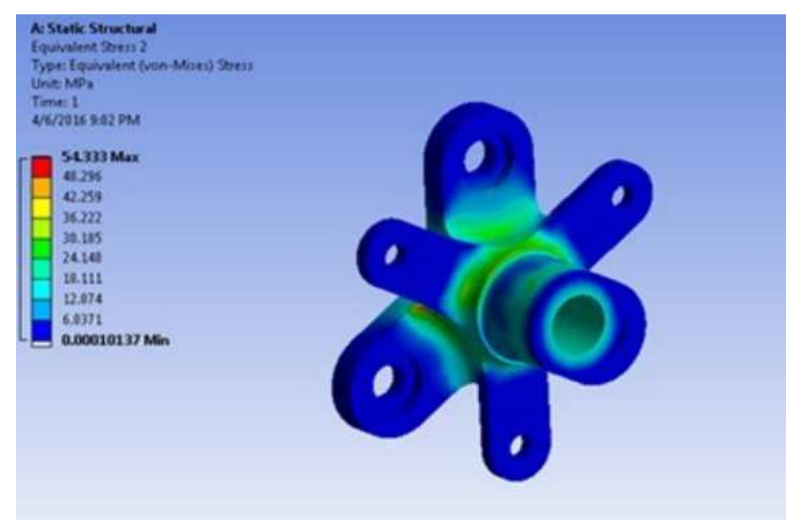

Figure 5: Total Stress for Al 7075 Material

The above figure shows the result of total stress of the hub for the Al 7075 by using the ANSYS workbench software. In the figure 5 the multi colors are showed. The colors denote the safe and unsafe portions of the hub. The blue color denotes the minimum stress and the green color denotes the maximum stress.

From the results, it is clear that the stress concentration is higher in the EN8 content when compared to the EN24 and Al 7075 materials. So the EN8 is the suitable material for wheel hub of the student formula race cars.

\section{CONCLUSIONS}

Keeping in mind the end goal to beat the trouble of supplanting the brake plate from the wheel centre point of SF auto and to lessen the heaviness of wheel centre point, another model of wheel centre is intended for SF autos. The outline is done in light of the necessities; loads following up on the wheel centre, the required least weariness life of the wheel centre and the reasonable anxiety sufficiency. Reproduction investigation was done utilising ANSYS Workbench 16.2. From the consequences of the examination, it has discovered that the plan is sheltered up to the required number of exhaustion life cycles and furthermore the weight is reduced when contrasted with OEM centres.

\section{REFERENCE}

1. Yang, Y. P., Luh, Y. P. and Cheung, C. H., (2004). Design and control of axial-flux brushless DC wheel motors for electric vehicles-part I: Multi objective optimal design and analysis. IEEE Transactions on Magnetics, 40(4), pp.1873-1882. 
2. Wrobel, R. and Mellor, P. H., (2008). Design considerations of a direct drive brushless machine with concentrated windings. IEEE Transactions on energy conversion, 23(1), pp.1-8.

3. Luo, S. J., Fu, Y. T. and Zhou, Y. X., (2012). Perceptual matching of shape design style between the wheel hub and car type. International Journal of Industrial Ergonomics, 42(1), pp.90-102.

4. Vogwell, J., (1998). Analysis of a vehicle wheel shaft failure. Engineering Failure Analysis, 5(4), pp.271-277.

5. JAYAKUMAR', N., MOHANAMURUGAN, S., \& RAJAVEL, R. (2014). DESIGN AND ANALYSIS OF GATING SYSTEM FOR PUMP CASING.

6. Riley, W. B., \& George, A. R. (2002). Design, analysis and testing of a formula SAE car chassis (No. 2002-01-3300). SAE Technical Paper.

7. Viswa Mohan Pedagopu \& Manish Kumar, Design and Machining Simulation of a Prismatic Part Using NX CAD/CAM an Overview, International Journal of Mechanical and Production Engineering Research and Development (IJMPERD), Volume 4, Issue 1, January - February 2014, pp. 23-28

8. Theander, A. (2004). Design of a suspension for a formula student race car. Vehicle dynamics, Aeronautical and vehicle engineering, Royal Institute of Technology.

9. Jawad, B. A., \& Polega, B. D. (2002). Design of Formula SAE Suspension Components (No. 2002-01-3308). SAE Technical Paper.

10. Shaik, A. F. B., \& Srinivas, C. L. (2012). Structural and thermal analysis of disc brake with and without cross-drilled rear of the race car. International Journal of Advanced Engineering Research and Studies, 1(4), 39-43.

11. Gaffney, E. F., \& Salinas, A. R. (1997). Introduction to Formula SAE® Suspension and Frame Design (No. 971584). SAE Technical Paper.

12. Craig, C., \& Passmore, M. A. (2014). Methodology for the Design of an Aerodynamic Package for a Formula SAE Vehicle. SAE International Journal of Passenger Cars-Mechanical Systems, 7(2014-01-0596), 575-585.

13. Popa, C. E. (2005). Steering system and suspension design for 2005 formula SAE-a racer car. Bachelor of Engineering (Mechanical) Dissertation, University of Southern Queensland.

14. Bakar, M. A., Mansor, M. R., Akop, M. Z., Rosli, M. M., \& Salim, M. A. (2011). Thermal analysis of VenTilaTed disc Brake roTor for UTem formUla VarsiTy race car. Journal of Engineering and Technology (JET), 2, 106-116.

15. Salter, J. I., \& Wittek, A. (2011). Design, Analysis and Manufacture of 2011 REV Formula SAE Vehicle Chassis (Doctoral dissertation, thesis paper, The University of Western Australia, October 17).

16. A. Aravindkumar, (2014) "CFD analysis of gas flow behaviour in various economizer duct" International Journal of MC Square Scientific Research(IJMSR), vol.6, no.1. pp-61-65. 
